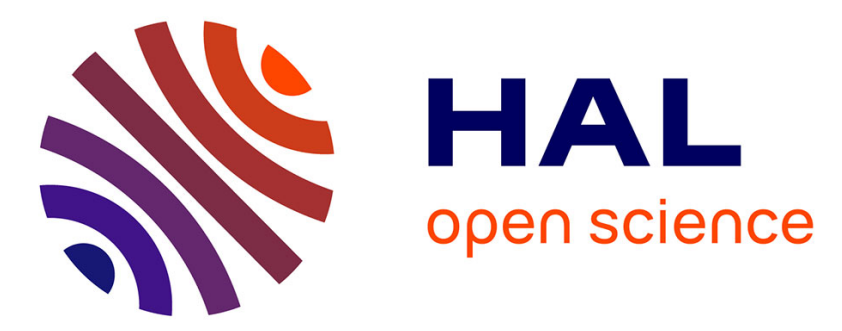

\title{
Fabrication of biomimetic titanium laminated material using flakes powder metallurgy
}

\author{
Diaa Mereib, U-Chan Chung, Mirvat Zakhour, Michel Nakhl, Nicolas \\ Tessier-Doyen, Jean-Louis Bobet, Jean-François Silvain
}

\section{To cite this version:}

Diaa Mereib, U-Chan Chung, Mirvat Zakhour, Michel Nakhl, Nicolas Tessier-Doyen, et al.. Fabrication of biomimetic titanium laminated material using flakes powder metallurgy. Journal of Materials Science, 2018, 53 (10), pp.7857-7868. 10.1007/s10853-018-2086-x . hal-01737289

\author{
HAL Id: hal-01737289 \\ https://hal.science/hal-01737289
}

Submitted on 2 Feb 2021

HAL is a multi-disciplinary open access archive for the deposit and dissemination of scientific research documents, whether they are published or not. The documents may come from teaching and research institutions in France or abroad, or from public or private research centers.
L'archive ouverte pluridisciplinaire HAL, est destinée au dépôt et à la diffusion de documents scientifiques de niveau recherche, publiés ou non, émanant des établissements d'enseignement et de recherche français ou étrangers, des laboratoires publics ou privés. 


\title{
Fabrication of biomimetic titanium laminated material using flakes powder metallurgy
}

Diaa Mereib ${ }^{a, c}$, U-Chan Chung Seu ${ }^{c}$, Mirvat Zakhour $^{a}$, Michel Nakhl $^{a}$, Nicolas Tessier-Doyen ${ }^{b}$, Jean-louis Bobet ${ }^{c}$, Jean-François Silvain ${ }^{c}$

a Laboratoire de Chimie Physique des matériaux (LCPM)/PR2N, Faculté des sciences, Université Libanaise, Fanar, PO Box 90656 Jdeidet El Metn, Liban

${ }^{\mathrm{b}}$ SPCTS, F-33600 Limoges, France

${ }^{c}$ CNRS, Univ. Bordeaux, ICMCB, UPR 9048, F-33600 Pessac, France

\begin{abstract}
Inspiring from the microstructure of the nature biological materials, a laminated titanium material was successfully elaborated using a novel approach of flakes powder metallurgy called "flakes powder metallurgy". Ti flakes powder used as building blocks of the layers microstructure were prepared by ball milling. They are than assembled into fully dense laminated material using Spark Plasma Sintering (SPS) techniques. The results show i) an anisotropy microstructure of the sintered material prepared from the flakes powder ii) $15 \%$ of contribution of the lamellar architecture in the strength (hardness) of the material iii) faster densification of the flakes powder compared to spherical powder.
\end{abstract}

\section{Keywords}

Titanium, lamellar structure, ball milling, flakes powder metallurgy, mechanical properties Corresponding authors

Email address: diaa.mereib@u-bordeaux.fr (D. Mereib), Jean-francois.Silvain@icmcb.cnrs.fr (JF. Silvain) 


\section{Introduction:}

Natural biological materials, such as teeth, bones and mollusk shells are characterized by a layered architecture that exhibits excellent mechanical properties. Inspired from the lamellar architecture of nacre, the efforts were increased for the fabrication of lamellar composite material called biomimetic materials which showed desirable mechanical properties [1-6]. Different techniques are used for the fabrication of this multilayered architecture materials, such as diffusion welding, adhesion welding, physical and chemical deposition and hot rolling [6-10]. Recently, a new process called "flakes powder metallurgy" has been used for the fabrication of lamellar material matrix composite (MMC). The aim of this process is to sinter metallic powder or metallic flakes, prepared by ball milling, with controlled microstructure in order to obtain lamellar architectures. Aluminum and copper laminated composite materials such as, $\mathrm{Al} / \mathrm{Al}_{2} \mathrm{O}_{3}, \mathrm{Al} /$ carbon nanotubes, $\mathrm{Al} /$ graphene, $\mathrm{Al} / \mathrm{B}_{4} \mathrm{C}, \mathrm{Cu} / \mathrm{Carbon}$ nanotubes, have been prepared using this technique showing improved tensile strength, Young's modulus and toughness properties. It was reported that lamellar flakes architecture, with high aspect ratio and refined metal grains induced by the ball milling process, allow to increase the strength of the material while conserving the material' $s$ ductility [11-15].

During the ball milling process, the powder undergoes a succession of ball collisions that induce the deformation of the initial metallic powders. Studies have reported that during the early stage of ball milling of ductile metals, the formation of flakes is observed before the fracture of the powders which can be attributed to plastic deformation (micro-rolling) of the metallic powder [14]. On the other hand, the use of different control agents, such as stearic acid or ethylen bis-stearamid, was used during high energy ball milling of ductile metals ( $\mathrm{Al}, \mathrm{Cu}, \mathrm{Ni}$ ). These agents impede the clean metal-metal contact and prevent excessive cold welding enhancing flakes formation. However, these agents tend to decompose during milling and induce contamination of the flake surface [15].

Titanium and titanium alloys are widely used in different sectors such as biomedical, aeronautic, automotive, and industrial due to their combination of excellent specific mechanical properties, light weight, biocompatibility and corrosion resistance $[19,20]$.

Recently, studies are focused on the fabrication of laminated titanium composite materials. For example, laminated $\mathrm{Ti} / \mathrm{La}_{2} \mathrm{O}_{3}, \mathrm{Ti} / \mathrm{TiB}_{2}, \mathrm{Ti} / \mathrm{Ti}-\mathrm{TiB}, \mathrm{Ti}-\mathrm{Ti}(\mathrm{Al}) / \mathrm{TiB}, \mathrm{Ti}-\mathrm{Al}{ }_{3} \mathrm{Ti}$ metal-intermetallic composite materials show improved mechanical properties such as ductility, strength and high fracture toughening [20-22].

In the present work, we study the use of flakes powder metallurgy for the fabrication of laminated titanium materials (strategy illustrated on Figure 1) and the contribution of the lamellar architecture on the improvement of titanium mechanical properties. We discuss the effect of the powder shape (flakes or spherical powder) on (i) the densification, (ii) the 
microstructure and (iii) the mechanical properties of the laminated sintered materials. In this process, Ti spherical powders were ball milled to obtain Ti flakes with controlled geometry and microstructure. The powders are then sintered using Spark Plasma Sintering (SPS) technique that allows the fast densification of the Ti flakes keeping the initial architecture of the Ti grain (flakes) and limiting grain growth. The microstructure and the mechanical properties (elasticity and hardness) of the final material are studied. This work must be considered as a first step through the fabrication of Ti lamellar composite materials.

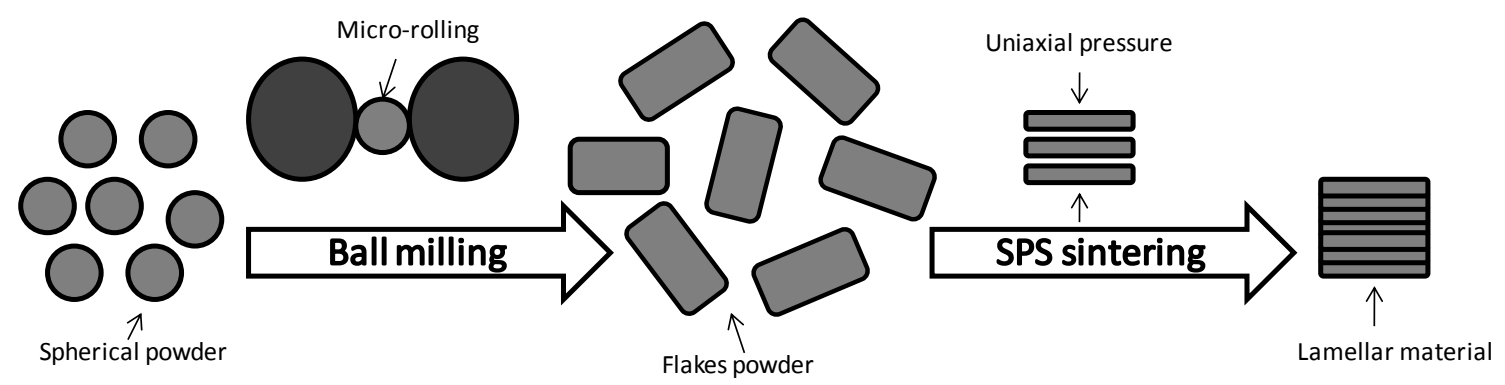

Figure 1: Typical strategy followed for the fabrication of the Ti laminated material.

\section{Experimental procedures}

\section{1- Ti powder elaboration}

Titanium flakes powder is obtained by ball milling (BM) using a planetary mill (Fritsch Planetary Mill) using stainless steel balls (diameter 5 and $10 \mathrm{~mm}$ ) and metallic vials (volume $150 \mathrm{~mL}$ ). In our work, almost spherical titanium powder (Ti, purity=99.5\%, CERAC Inc) $d_{50}=(48 \mu \mathrm{m})$ is used as the initial material. BM is performed under argon atmosphere at $200 \mathrm{rpm}, 20: 1$ balls to powder ratio with 2 wt. \% of sodium chloride $(\mathrm{NaCl})$ as lubricant. All the handlings were performed inside a glove box to reduce atmospheric contamination. The as-prepared Ti flakes were then washed with water during $2 \mathrm{~min}$, to remove $\mathrm{NaCl}$, and then filtrated.

\section{2- Ti powder consolidation}

SPS process was chosen as sintering technique. DR SINTER LAB Spark plasma sintering system (model SPS 515-S) apparatus was used. A graphite die, covered by carbon felt is used to prepare samples of $10 \mathrm{~mm}$ of diameter. The temperature is measured by a K-type thermocouple inserted in the die wall. The sintering process was performed under vacuum using the following conditions: temperature was raised up to $600^{\circ} \mathrm{C}$ at $100{ }^{\circ} \mathrm{C} / \mathrm{min}$ and maintained during $10 \mathrm{~min}$ with a pressure of $100 \mathrm{MPa}$ applied at RT temperature and kept constant during the whole experiment. 


\section{3- Characterization}

The morphology and the microstructure of the materials before and after sintering were studied using a scanning electron microscope (SEM) (TESCAN VEGA) on mechanically polished (surface and cross sections) samples. The mean particle size and particle size distribution before and after ball milling were measured using a laser granulometer (Mastersizer 2000). The density of the sintered materials was determined using the Archimedes principle. Samples before and after sintering were characterized by X-ray diffraction (XRD). Powder X-ray diffraction (XRD) patterns were collected on a PANalitycal X'pert PRO MPD diffractometer in Bragg-Brentano $\theta-\theta$ geometry equipped with a secondary monochromator and X'Celerator multi-strip detector. Each measurement was made within an angular range of $2 \theta=8-80^{\circ}$ and lasted for 34 minutes. The Cu-K $\alpha$ radiation was generated at $45 \mathrm{KV}$ and $40 \mathrm{~mA}$ ( $\lambda=1.5405$ $\left.A^{0}\right)$.The crystallite size and the lattice strain was determined by Williamson-Hall method using the integral width of the whole peaks.

The hardness of the polished materials was measured using Vickers hardness tester model 452 SVD, at a $50 \mathrm{Kg}$ load and $10 \mathrm{~s}$ dwell time. Elastic constants (Young's modulus, shear modulus) were determined at room temperature by ultrasonic pulse, using $10 \mathrm{MHz}$ transducers working in reflection mode on $3 \mathrm{~mm}$ thick sample.

\section{$\underline{\text { Results }}$}

\section{Elaboration of titanium flakes}
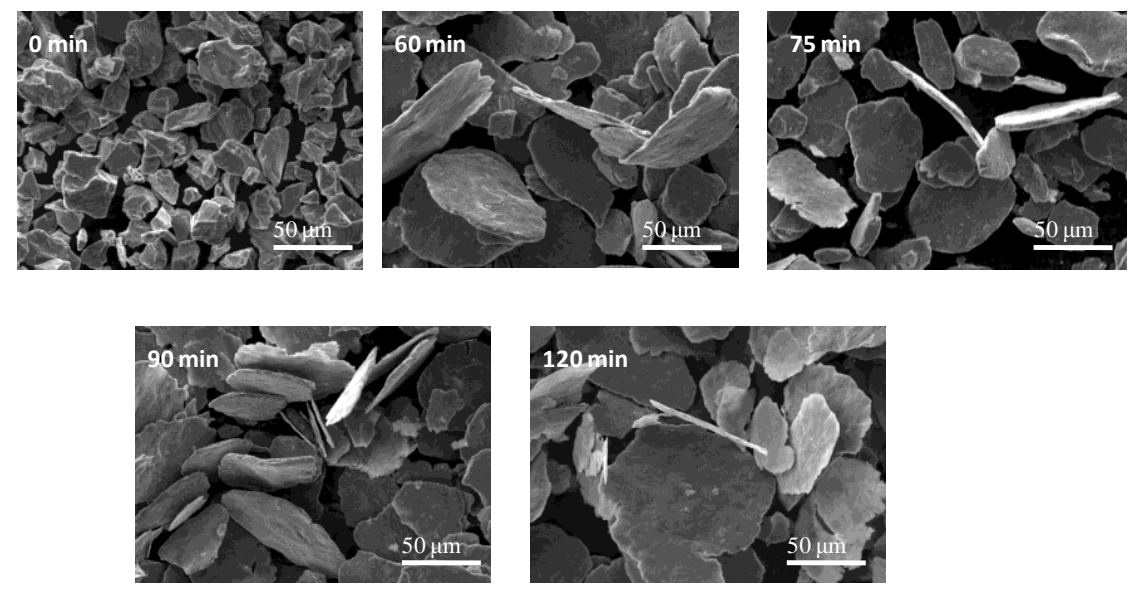

Figure 2: SEM micrographs of Ti before (0 min) and after different BM duration (65, 75, 90 and $120 \mathrm{~min})$ 


\section{- Flakes morphology}

Figure 2 shows the effect of BM time on the morphology change of the initial Ti powder. After 60 min of BM, the Ti powder present a 2D platelet like morphology with an average diameter of $40 \mu \mathrm{m}$, a thickness of $3.5 \mu \mathrm{m}$ and an aspect ratio (diameter/thickness) of 11. The increase of BM time up to $120 \mathrm{~min}$, allow the elaboration of thin flakes ( $1 \mu \mathrm{m}$ of thickness) with larger diameter $(65 \mu \mathrm{m})$, and an increase of the aspect ratio up to 65 as shows in Erreur! Source du renvoi introuvable.

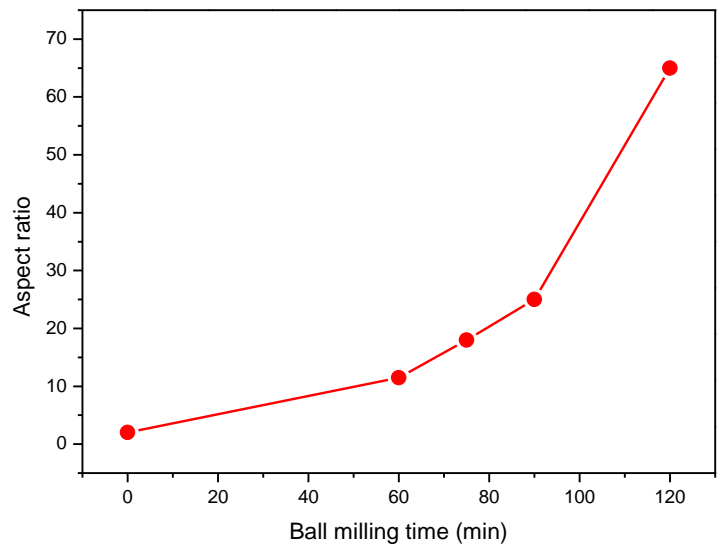

Figure 3: Evolution of the aspect ratio of Ti powder with BM times.

The use of the $\mathrm{NaCl}$ as a process control agent, during the $\mathrm{BM}$ process, is essential for the production of flake shaped particles as shows the Figure 4. This lubricant avoids Ti powders agglomeration and fracture and decreases the friction energy between balls and particles.
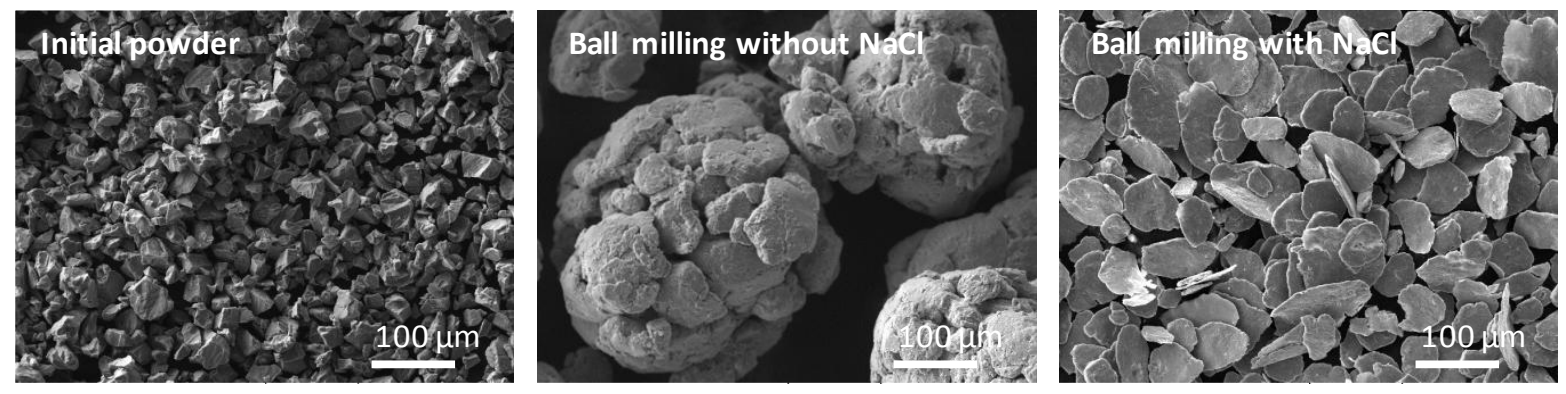

Figure 4: SEM micrographs of Ti powders before BM (initial powder), and after 60 min of BM with and without the use of $\mathrm{NaCl}$.

\section{- Flakes orientation}




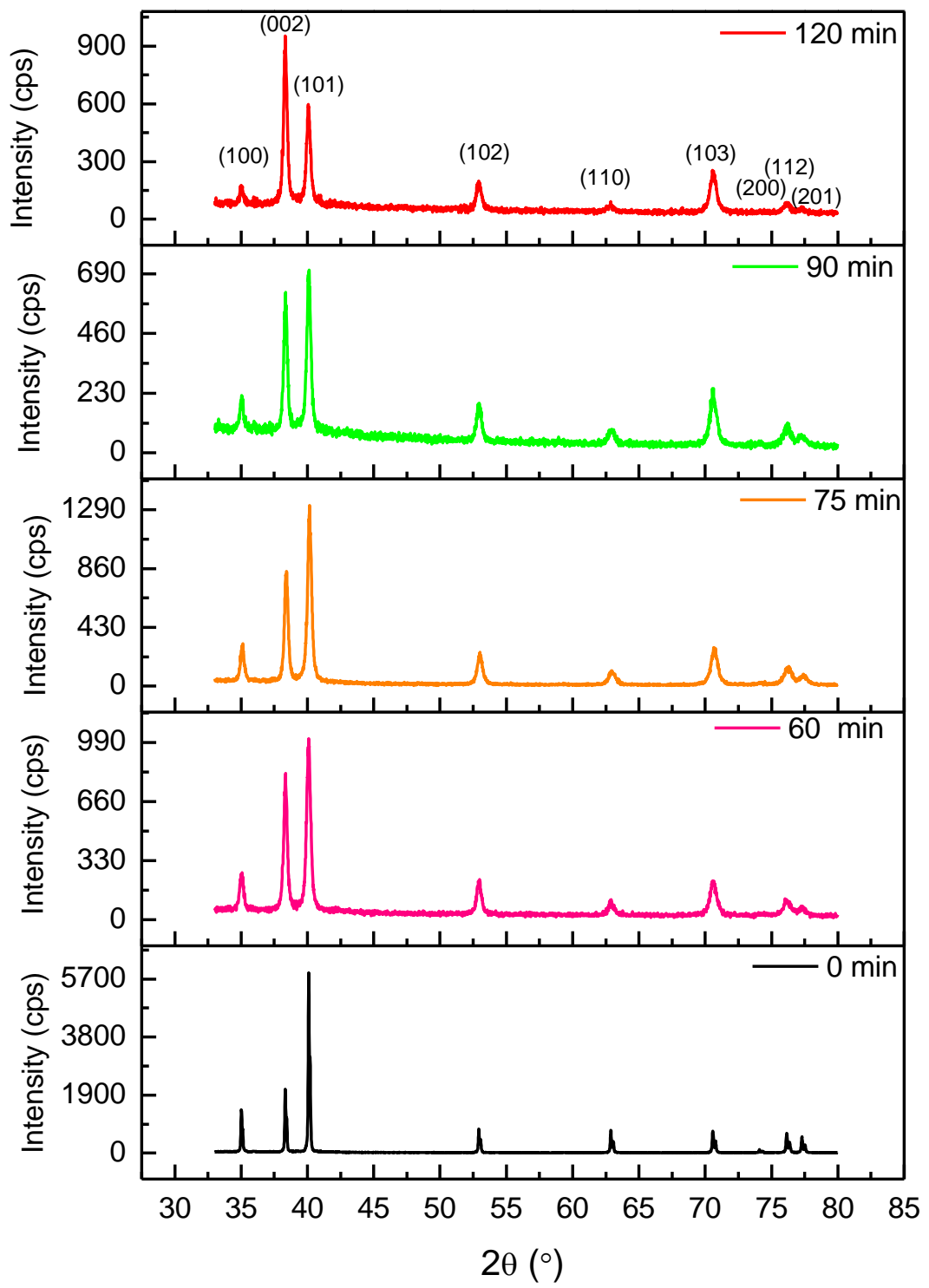

Figure 5: X-ray diffractions pattern of Ti flakes powder prepared at different BM time.

Erreur! Source du renvoi introuvable. shows the XRD pattern of the Ti powder, prepared at different BM times. By comparing the XRD patterns obtained for initial powder $(0 \mathrm{~min})$ and after $60 \mathrm{~min}$ of BM, it appears a decrease of the peak intensities and broadening. These 2 effects can be attributed to the increase of the crystal defects (dislocations, vacancies ...) and of the lattice strain and also to the decrease of the crystallite size. Furthermore, after BM process, 
the relative intensities of the (00l) plane become larger than the (hk0) one. In parallel, the calculation of the percentage of (002) oriented grains, using the following formula [21]:

$P_{\mathrm{O}(002)}=\mathrm{I}_{(002)} / \Sigma \mathrm{I}_{(\mathrm{hkl})} \quad \mathrm{I}_{(\mathrm{hkl})}$ : Intensity of the (hkl) plane

shows in the Figure 6, permits to follow the change of Ti flake orientation with increased BM time. That behavior confirms that the (002) preferred orientation occurs and increases with BM duration.

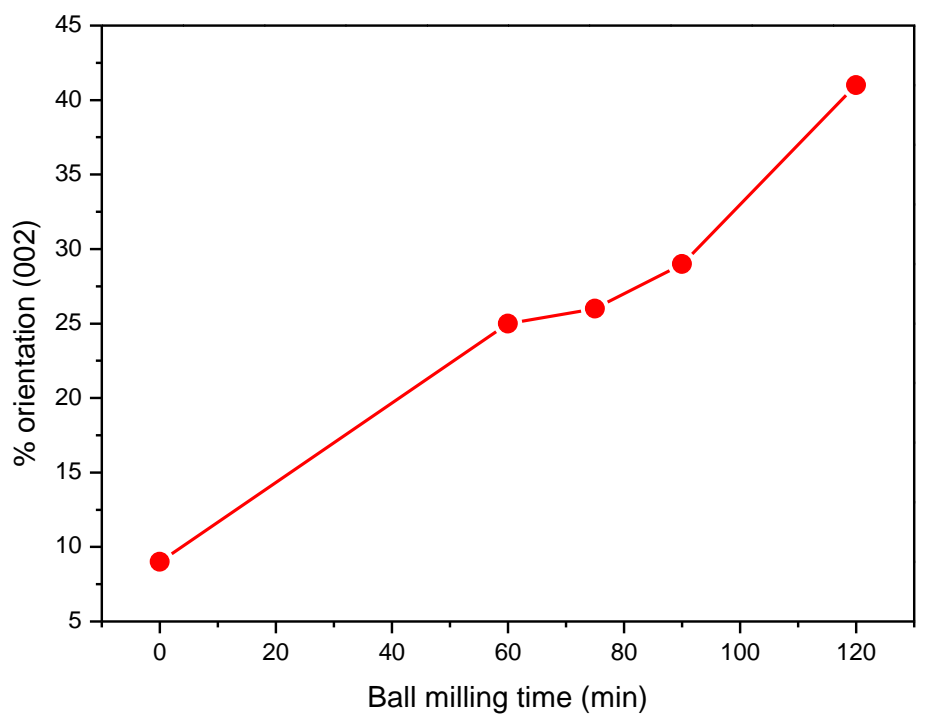

Figure 6: Percentage of (002) plane orientation of Ti grain as function of BM duration.

\section{Sintering of the Ti flakes}

- "Flakes" versus "spherical" powder densification and microstructure. 

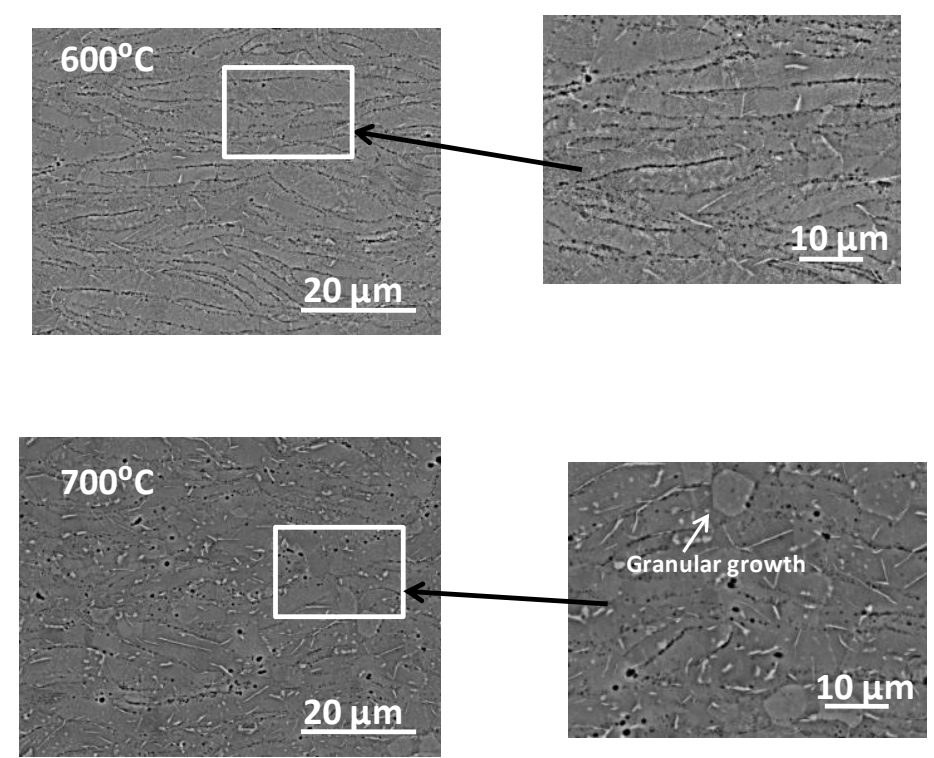

Figure 7 : SEM micrographs of sintered Ti prepared from flakes powder and densify at different temperatures.

As shows from Erreur! Source du renvoi introuvable., after SPS densification the presence of lamellar architecture with respect to the sintering temperature is highlighted. Under a uniaxial pressure, applied during SPS, the Ti flakes orientate and tend to lie flat one on each other leading to an oriented lamellar architecture. However, at $700{ }^{\circ} \mathrm{C}$ (and higher) granular growth takes place and deteriorate the lamellar microstructure.

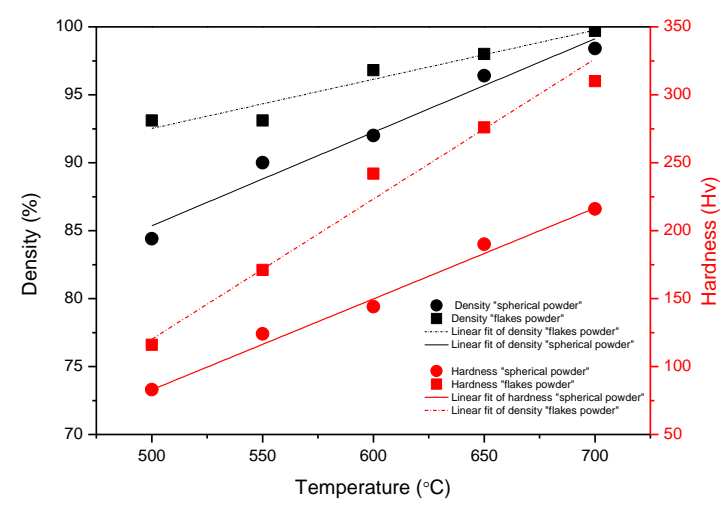

a.

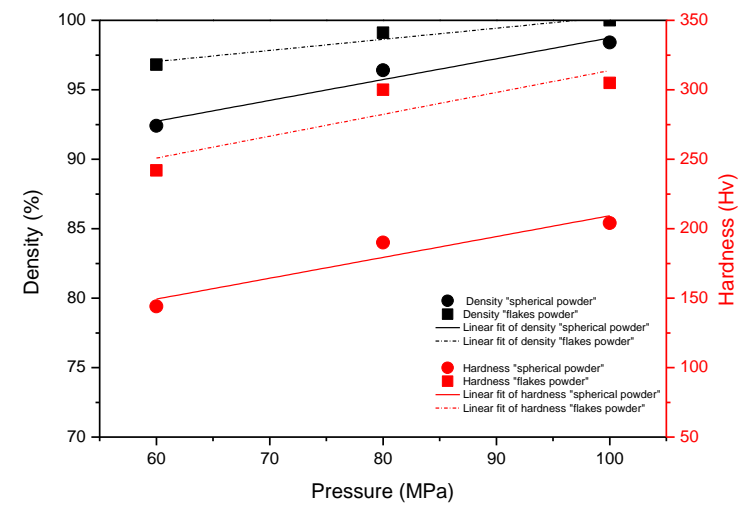

b.

Figure 8: Density and hardness of sintered Ti materials for a) different temperatures at $60 \mathrm{MPa}$ and b) different pressure at $600^{\circ} \mathrm{C}$

The density when sintering "spherical" powder is always lower that when sintering the "flakes" powder whatever the temperature and the applied pressure (Figure 8). At $600^{\circ} \mathrm{C}$ the density linearly increase with the apply pressure for both spherical and flake powders (Fig. 8b); same 
phenomena can be observed at $60 \mathrm{MPa}$ for increasing temperature (Figure 8a). At $600{ }^{\circ} \mathrm{C}$ and under $100 \mathrm{MPa}$, the flake powders are fully dense when in the case of the "spherical" powder $1.5 \%$ of residual porosity persists.

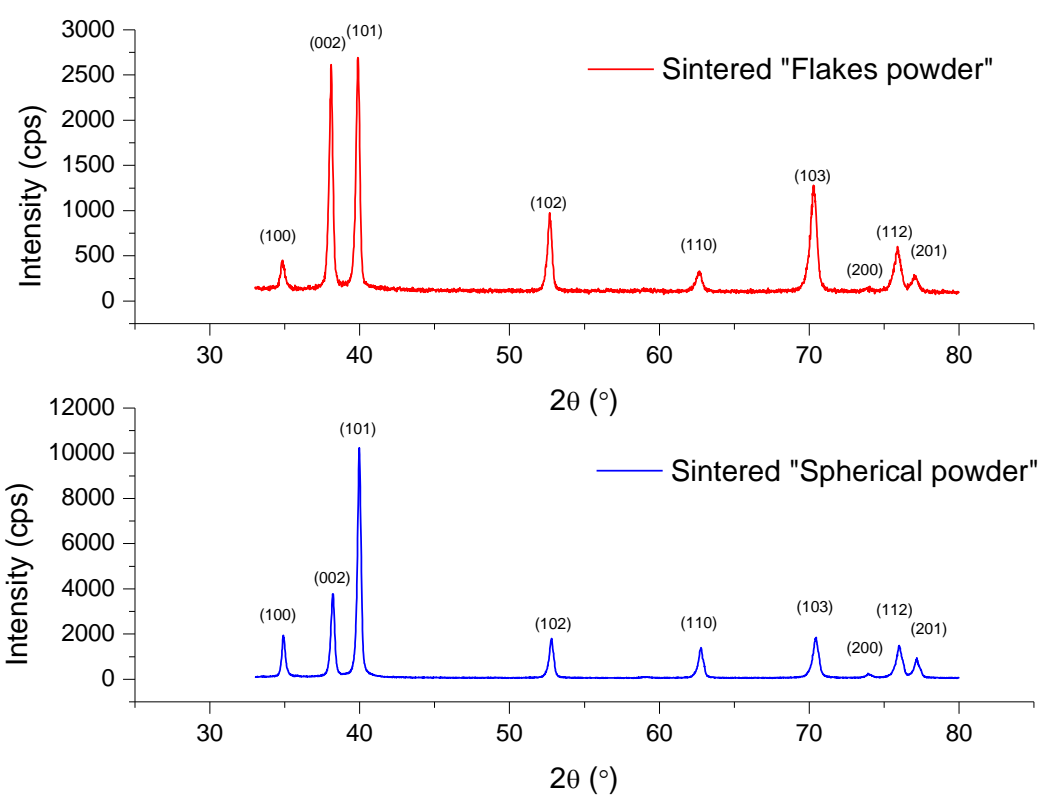

Figure 9: X-ray diffraction patterns of Ti "Spherical" (bottom) and "flakes" (up) sintered powder.

The XRD patterns of sintered materials fabricated using "flakes" and "spherical" powders are shown in Figure 9. In the case of sintered flakes, we can observe, for all diffraction peaks, width broadening and intensity decrease. Both two behaviors are associated with the refinement of the microstructure and the lattice strains which is created during ball milling. However, the relative peak intensity of the (002) plane, is higher than the one of the sintered spherical powder. This behavior indicates the conservation of the (002) orientation after sintering of the Ti flakes which is linked with the anisotropic microstructure of the sinter materials.

\section{Hardness and Young's modulus properties}

The Figure 8: Density and hardness of sintered Ti materials for a) different temperatures at $60 \mathrm{MPa}$ and b) different pressure at $600^{\circ} \mathrm{C}$ shows the hardness values obtain for materials sintered under different conditions. As for the density, an increase of the hardness values with the temperature, at a given pressure $(60 \mathrm{MPa})$, (Figure $8 \mathrm{a})$ and with the pressure, at a given temperature $\left(600^{\circ} \mathrm{C}\right)$, (Figure $8 \mathrm{~b}$ ) has been observed. In the case of sintered Ti flakes, the hardness and density increases from $116 \mathrm{Hv}$ and $92 \%$ to $310 \mathrm{Hv}$ and $100 \%$ respectively. Likewise, in the case of "spherical" powder the hardness increase from $83 \mathrm{Hv}$ and $85 \%$ of density to $204 \mathrm{Hv}$ and $98.5 \%$ of density. 
The Figure 8 shows that, for the same density value, the hardness of a sintered material made from "flakes" powder is higher than the one made from "spherical powder". For example, at 98.5\% of density, the hardness of the sintered flakes powder is $277 \mathrm{Hv}$, while the one of the sintered spherical powder is only $204 \mathrm{Hv}$. This increase should be linked with the refinement of the microstructure induced during the ball milling and/or with the lamellar architecture of $\mathrm{Ti}$ flakes sintered material.

The Table 1 shows the Young's modulus and the hardness measured on sintered materials prepared with "spherical" and "flake" powders. Young's modulus and hardness of spherical powders increase respectively from $102 \mathrm{GPa}$ and $187 \mathrm{Hv}$ at $97 \%$ of density to $117 \mathrm{GPa}$ and 209 $\mathrm{Hv}$ at fully density. Also, for full dense sintered material, the hardness increase from $207 \mathrm{Hv}$ (spherical powder) to $305 \mathrm{Hv}$ (flakes powder). In parallel, the crystallite size of the initial powders decreases from $77 \mathrm{~nm}$ (spherical powder) to $30 \mathrm{~nm}$ (flakes powder) due to the ball milling. However, the Young's modulus remains the same (117 GPa) for fully dense material prepared from spherical and flakes powder.

Table 1: Crystallites size and lattice strain of " spherical" and "flakes "powder (before sintering) (blue), and hardness and Young modulus values of materials sintered with each powder (red).

\begin{tabular}{|cccc|}
\hline Material & $\begin{array}{c}\text { "Spherical" powder } \\
\text { sintered at } 600{ }^{\circ} \mathrm{C}\end{array}$ & $\begin{array}{c}\text { "Spherical" powder } \\
\text { sintered at } 700^{\circ} \mathrm{C}\end{array}$ & $\begin{array}{c}\text { "Flakes" powder } \\
\text { (60 min of ball milling) } \\
\text { sintered at } 600{ }^{\circ} \mathrm{C}\end{array}$ \\
\hline $\begin{array}{c}\text { Powder crystallite size } \\
(\mathrm{nm})\end{array}$ & 77 & 77 & 30 \\
\hline $\begin{array}{c}\text { Density of the sintered } \\
\text { material (\%) }\end{array}$ & 97 & 99.3 & 99.5 \\
\hline $\begin{array}{c}\text { Surface hardness of the } \\
\text { sintered material (Hv) }\end{array}$ & $187 \pm 2$ & $209 \pm 5$ & \\
\hline $\begin{array}{l}\text { Young's modulus of the } \\
\text { sintered material (GPa) }\end{array}$ & $102 \pm 2$ & $117 \pm 2$ & $117 \pm 2$ \\
\hline
\end{tabular}

Table 2: Crystallites size and lattice strain of " spherical" and "flakes "powder (before sintering) (blue), and hardness (parallel and perpendicular to the flake plane) and Young modulus values of materials sintered with each powder (red).

\section{Material}

"Milled non-flakes" powder (60 min of ball milling)
"Flakes" powder (60 min of ball milling) 


\begin{tabular}{|ccc|}
\hline Powder crystallite size (nm) & 31 & 30 \\
\hline Lattice strain (\%) & +0.08 & +0.1 \\
\hline $\begin{array}{c}\text { Density of the sintered material } \\
(\%)\end{array}$ & 99.7 & 99.5 \\
\hline $\begin{array}{c}\text { Surface hardness of the } \\
\text { sintered material (Hv) }\end{array}$ & $261 \pm 305 \pm 5$ \\
\hline $\begin{array}{c}\text { Cross-section hardness of the } \\
\text { sintered material (Hv) }\end{array}$ & $282 \pm 3$ \\
\hline
\end{tabular}

In order to highlight the effect of the Ti lamellar architecture on its mechanical properties, dense Ti materials, fabricated with ball milled powders, which have been prepared with and without $\mathrm{NaCl}$ control agent, have been analyzed. As seen on Figure 4, both powders present completely different morphology: almost spherical for the powders ball milled without $\mathrm{NaCl}$ and plate like for the other one. As seen on table 2, the "milled non-flakes" and the "flakes" powder have almost the same crystallite size and lattice strain. However, the hardness of the lamellar Ti material, prepared from "flakes" powders, is higher than those prepared with "milled non-flakes" powders. It means that such increase is linked with the architecture (lamellar structure) of the material.

Anisotropy values of hardness in the case of lamellar material are observed (see table 2); the hardness measured on the cross-section of the sinter material is lower than that of the surface one. In the case of the sintered material, prepared from flakes ball milled during $60 \mathrm{~min}$, the hardness of the surface is $8 \%$ higher than this of the cross section whereas no difference is observed in the case of the materials prepared with "ball milled non-flakes" powder.

Figure 10 shows the effect of the increase of ball milling time on the hardness of the lamellar material prepared by this flakes powder. The hardness (surface and cross section) increase with the increase of ball milling times and reach, after $120 \mathrm{~min}$ of $\mathrm{BM}, 386 \mathrm{Hv}$ and $368 \mathrm{Hv}$ on the surface and cross-section, respectively. Furthermore, the difference of the hardness values is kept constant whatever the BM time (close to $6 \%$ between surface and cross section). In parallel, Young's modulus of lamellar Ti material (121 GPa) (120 min of BM), as shown from the Table 3, is 4\% higher than that of those prepared during $60 \mathrm{~min}$ (117 GPa). 


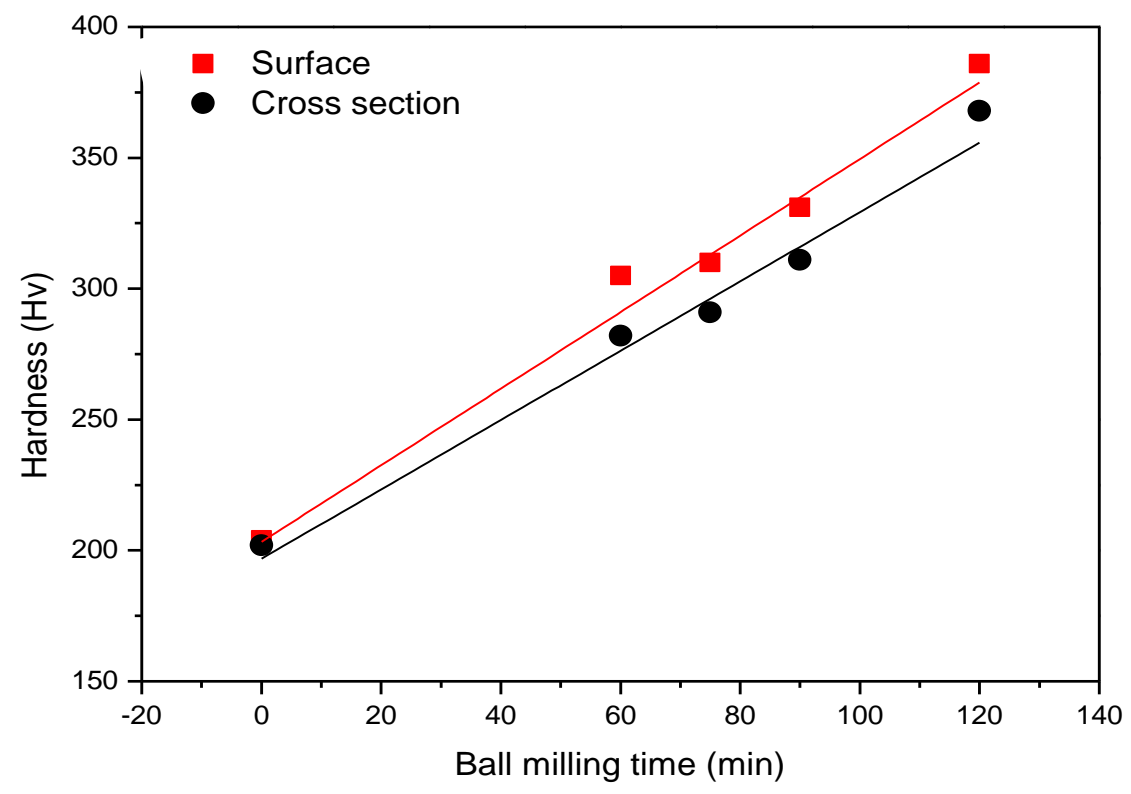

Figure 10: Hardness of sintered Ti flakes prepared at different ball milling times.

Table 3: Crystallites size of " spherical" and "flakes "powder (before sintering) (blue), and hardness (parallel and perpendicular to the flake plane) and Young's modulus values of materials sintered with each powder (red).

\begin{tabular}{|ccc|}
\hline Material & $\begin{array}{c}\text { "Flakes" powder } \\
\text { (60 min of ball milling) }\end{array}$ & $\begin{array}{c}\text { "Flakes" powder } \\
\text { (120 min of ball milling) }\end{array}$ \\
\hline Powder cristallite size (nm) & 30 & 30 \\
\hline Lattice strain (\%) & +0.08 & +0.1 \\
\hline $\begin{array}{c}\text { Density of the sintered material (\%) } \\
\text { Surface hardness of the sintered } \\
\text { material (Hv) }\end{array}$ & 99.5 & $386 \pm 3$ \\
\hline $\begin{array}{c}\text { Cross section hardness of the } \\
\text { sintered material (Hv) }\end{array}$ & $305 \pm 5$ & $368 \pm 4$ \\
\hline Young's modulus (GPa) & $282 \pm 3$ & $121 \pm 2$ \\
\hline
\end{tabular}




\section{Discussion}

\section{Flakes powder morphology and texture}

During the micro-rolling, plastic deformation occurs on the surface of the grains which causes the formation of the flakes shape. This plastic deformation is shown to increase with the BM time. Additional micro-rolling of the Ti flakes induce an increase of the flaking behavior as shown in the figure 3 by the increase of the aspect ratio. Studies attribute this flaking behavior to 1) anisotropic elastic modules of $\mathrm{Ti}$ and 2) the presence of planes which are "softer" than others and to the twining mechanism that occur during ball milling [23].

In parallel, flakes powder texture represented in the figure Figure 5 follow the basal plan (002), where the intensity of the (002) plane become higher than that of the (101). The increase of BM time up to $120 \mathrm{~min}$, bring additional crystal defect and lattice strain, that lead to further decrease of all the peak intensity and broadening; these effect can be easily observed on the more intense (101) plane.

\section{Flakes powder versus spherical powder densification and microstructure.}

The higher ability of flakes powder to densify, compared to spherical powder as show in the figure Figure 8 can be attributed to:

- The flakes morphology that allows i) the alignment of the particles with minimum interparticle volume, ii) a higher compressibility before heating, and iii) a reduction of the diffusion paths during sintering.

- The high aspect ratio of the flakes, that gives rise to higher surface energy. Ended, for the flakes powder, atomic array at the surface of the flakes has greater energy than the bulk leading to an enhancement of the sintering behavior compared to spherical powder.

- The high crystal defect density induced by ball milling process that promotes solid diffusion

\section{Hardness}

Microstructure and relative density (or remaining porosity), have some effects on the hardness of the tested materials. The relative role of each is not straight forward even if it is well known that porosity reduces the amount of solid material available to resist to deformation. This explain the increase of the hardness of the sintered spherical powder with the increase of the sintering temperature and so the density as shown in the Table 1 [22].

In other hand, the hardness increase from $209 \mathrm{Hv}$ (spherical powders) to $304 \mathrm{Hv}$ (flake powders). In parallel, the crystallite size of the initial powders decreases from $77 \mathrm{~nm}$ (spherical powder) to $30 \mathrm{~nm}$ (flakes powder). This decrease of crystallite size, associated with an increase 
of the grain boundaries density, restrict the motion of the dislocations and cause the strengthening and the hardening of the material [23], [24]. Therefore, for the flake sintered materials, the refinement of the microstructure induced by ball milling, contribute to the increase of the hardness (49\%), additional the lamellar architecture effect.

Far from the ball milling contribution, the hardness of the milled non flakes powder is lower than this of flakes powder as show the Table 2. It indicates that the texture of the Ti layers and the lamellar microstructure contributes up to $15 \%$ on the increase of surface hardness. This enhancement is therefore attributed to the lamellar architecture of the material prepared with "flakes" powders. This strengthening effect of lamellar architecture and flakes texture were already reported in the flakes powder metallurgy of Al composites [25].

While, the anisotropy values of cross section and surface hardness in the case of lamellar material observed (see Table 2 ) is linked to:

- A crystallographic effect: hardness anisotropy is evident in textured titanium, and it's linked to orientations of the grains at the points of the indents. Previous study shows that for polycrystalline textured alpha titanium, hardness is strongly dependent on orientation, highest hardness being seen where indentation direction is normal to the basal plane (002). This is in agreement with other works on polycrystalline Ti-6Al-4V [26]. But this is in opposition to work carried out on pure titanium single crystals, were the maximum value of hardness is found when the long axis of the indenter is parallel to the plane (002) [27]. This difference was attributed to the impurities ( $\mathrm{N}$ and $\mathrm{O}$ ) that change the activity of slip systems and grain boundary effects.

- A geometrical effect: In the case of cross section indentation, the number of crossed interfaces is higher than surface section. Then if these interfaces are considered as weak bonding between the Ti flakes, it permits an easier propagation of the strain and so a decrease of the hardness.

Furthermore, with the increase of BM times the flakes surface undergoes an additional plastic deformation and work hardening that allow the increase of the hardening of the lamellar material. Also, the higher number of interfaces by the increase of BM times act as obstacles for the dislocations motion and can trap mobile dislocations which increase the probability for subsequent dislocation-dislocation interactions, leading to more significant strain hardening ability and an increase of the material hardness. The layers thickness effect, was studied in the $\mathrm{Ti} / \mathrm{TiB}$ and $\mathrm{Al} / \mathrm{Al}_{2} \mathrm{O}_{3}$ laminated composite material; It was found that additional improvement of mechanical properties is brought by the decrease of lamellae thickness [11], [28].

\section{Young's modulus}

The young's modulus that describes the stiffness of the material is related essentially to the atomic bounding and the electronic states of the material. It isn't affected by the metallurgical processes such as heat treatment and plastic working, which bring modifications only in the 
microstructure [29]. However, it's responsive to the density and the interstitial solute content. It was found that interstitial and substational $\alpha$-stabilizing $(O, N \ldots)$ solutes increase the elastic properties [30].

So the increase of the Young's modulus with the increase of the sintering temperature of the spherical powder as shown in the Table 1 is related to the increase of density. However the lamellar microstructure doesn't affect the Young's modulus as the values for the sintered spherical powder and flakes powder are the same.

The increase of the Young's modulus of the lamellar Ti with the increase of the flakes BM times as shown in the Table 3 is related to the additional oxygen contamination brought by long BM duration.

\section{Conclusion}

Flakes shape $\mathrm{Ti}$ powder (002) grain oriented were prepared by ball milling of "Spherical" powder. An increase of their aspect ratios and their grain preferred orientation in respect to the increase of ball milling times was observed. The consolidation of this flakes powder allows the elaboration of fully dense lamellar Ti material using SPS technique with an anisotropy microstructure detected by XRD diffraction and SEM observations. Although, the flakes powder showed a faster densification compared to spherical powder, due to (i) the high aspect ratios (ii) surface energy and (iii) crystals defects created by ball milling.

The resultant lamellar titanium material showed an improvement of the mechanical properties, It exhibited higher strength (hardness) compared to those prepared from spherical powder. It was demonstrated that the lamellar architecture contributes to the increase of $15 \%$ on the hardness of titanium. The strengthening was also attributed to the higher density and the refinement microstructure of the lamellar material.

\section{References}

[1] L. J. Bonderer, A. R. Studart, and L. J. Gauckler, "Bioinspired Design and Assembly of Platelet Reinforced Polymer Films," Science, vol. 319, no. 5866, pp. 1069-1073, Feb. 2008.

[2] A. Walther, I. Bjurhager, J.M. Malho, J. Pere, J. Ruokolainen, L.A. Ruokolainen, O. Ikkala, "Large-Area, Lightweight and Thick Biomimetic Composites with Superior Material Properties via Fast, Economic, and Green Pathways," Nano Lett., vol. 10, no. 8, pp. 27422748, Aug. 2010.

[3] C. Tamerler and M. Sarikaya, "Molecular biomimetics: Utilizing nature's molecular ways in practical engineering," Acta Biomater., vol. 3, no. 3, pp. 289-299, May 2007.

[4] S. Ohsaki, S. Kato, N. Tsuji, T. Ohkubo, and K. Hono, "Bulk mechanical alloying of Cu-Ag and $\mathrm{Cu} / \mathrm{Zr}$ two-phase microstructures by accumulative roll-bonding process," Acta Mater., vol. 55, no. 8, pp. 2885-2895, May 2007. 
[5] A. Sellinger, P.M. Weiss, A. Nguyen, Y. Lu, R. Assink, W. Gong, C.J. Brinker, "Continuous selfassembly of organic-inorganic nanocomposite coatings that mimic nacre," Nature, vol. 394, no. 6690, pp. 256-260, Jul. 1998.

[6] Z. Tang, N. A. Kotov, S. Magonov, and B. Ozturk, "Nanostructured artificial nacre," Nat. Mater., vol. 2, no. 6, pp. 413-418, Jun. 2003.

[7] S. Nambu, M. Michiuchi, J. Inoue, and T. Koseki, "Effect of interfacial bonding strength on tensile ductility of multilayered steel composites," Compos. Sci. Technol., vol. 69, no. 11-12, pp. 1936-1941, Sep. 2009.

[8] O. Oner Ekiz, A. F. Dericioglu, and H. Kakisawa, "An efficient hybrid conventional method to fabricate nacre-like bulk nano-laminar composites," Mater. Sci. Eng. C, vol. 29, no. 6, pp. 2050-2054, Aug. 2009.

[9] W. HE, C.H. Li, B.F. Luan, R.S. Qui, K. Wang, Z.Q. Li, Q. Lui, "Deformation behaviors and processing maps of CNTs/Al alloy composite fabricated by flake powder metallurgy," Trans. Nonferrous Met. Soc. China, vol. 25, no. 11, pp. 3578-3584, Nov. 2015.

[10] X. Z. Kai, Z.Q. Li, G.L. Fan, Q. Guo, D.B. Xiong, Y.S. Su, W.J. Lu, W.J. Moon, D. Zhang, "Enhanced strength and ductility in particulate-reinforced aluminum matrix composites fabricated by flake powder metallurgy," Mater. Sci. Eng. A, vol. 587, pp. 46-53, Dec. 2013.

[11] W. Zhang, Z. Li, L. Jiang, X. kai, X. Dai, G. Fan, Q. Guo, D. Xiong, Y. Su, D. Zhang, “Flake thickness effect of Al2O3/Al biomimetic nanolaminated composites fabricated by flake powder metallurgy," Mater. Sci. Eng. A, vol. 594, pp. 324-329, Jan. 2014.

[12] J. Wang, Z. Li, G. Fan, H. Pan, Z. Chen, and D. Zhang, "Reinforcement with graphene nanosheets in aluminum matrix composites," Scr. Mater., vol. 66, no. 8, pp. 594-597, Apr. 2012.

[13] T. Varol and A. Canakci, "The effect of type and ratio of reinforcement on the synthesis and characterization $\mathrm{Cu}$-based nanocomposites by flake powder metallurgy," J. Alloys Compd., vol. 649, pp. 1066-1074, Nov. 2015.

[14] J. S. Benjamin and T. E. Volin, "The mechanism of mechanical alloying," Metall. Trans., vol. 5, no. 8, pp. 1929-1934, Aug. 1974.

[15] A. Nouri and C. Wen, "Surfactants in Mechanical Alloying/Milling: A Catch-22 Situation," Crit. Rev. Solid State Mater. Sci., vol. 39, no. 2, pp. 81-108, Jan. 2014.

[16] H. J. Rack and J. I. Qazi, "Titanium alloys for biomedical applications," Mater. Sci. Eng. C, vol. 26, no. 8, pp. 1269-1277, Sep. 2006.

[17] W. D. Brewer, R. K. Bird, and T. A. Wallace, "Titanium alloys and processing for high speed aircraft," Mater. Sci. Eng. A, vol. 243, no. 1-2, pp. 299-304, Mar. 1998.

[18] J. Ma, Z. He, and G. E. B. Tan, "Fabrication and characterization of Ti-TiB2 functionally graded material system," Metall. Mater. Trans. A, vol. 33, no. 3, pp. 681-685, Mar. 2002.

[19] B. X. Liu, L. J. Huang, L. Geng, B. Wang, C. Liu, and W. C. Zhang, "Fabrication and superior ductility of laminated Ti-TiBw/Ti composites by diffusion welding," J. Alloys Compd., vol. 602, pp. 187-192, Jul. 2014.

[20] B. X. Liu, L.J. Huang, L. Geng, B. Kaveendran, B. Wang, X.Q. Song, X.P. Cui, “Gradient grain distribution and enhanced properties of novel laminated Ti-TiBw/Ti composites by reaction hot-pressing," Mater. Sci. Eng. A, vol. 595, pp. 257-265, Feb. 2014. 
[21] X. Xiao, Z. Zeng, Z. Zhao, and S. Xiao, "Flaking behavior and microstructure evolution of nickel and copper powder during mechanical milling in liquid environment," Mater. Sci. Eng. A, vol. 475, no. 1-2, pp. 166-171, Feb. 2008.

[22] H. Wang, Z. Z. Fang, and P. Sun, "A critical review of mechanical properties of powder metallurgy titanium," Int. J. Powder Metall. Princet. N. J., vol. 46, no. 5, pp. 45-57, Sep. 2010.

[23] Z. Z. Fang, P. Sun, and H. Wang, "Hydrogen Sintering of Titanium to Produce High Density Fine Grain Titanium Alloys," Adv. Eng. Mater., vol. 14, no. 6, pp. 383-387, Jun. 2012.

[24] A. V. Sergueeva, V. V. Stolyarov, R. Z. Valiev, and A. K. Mukherjee, "Advanced mechanical properties of pure titanium with ultrafine grained structure," Scr. Mater., vol. 45, no. 7, pp. 747-752, Oct. 2001.

[25] G. Fan, R. Xu, Z. Tan, D. Zhang, and Z. Li, "Development of Flake Powder Metallurgy in Fabricating Metal Matrix Composites: A Review," Acta Metall. Sin. Engl. Lett., vol. 27, no. 5, pp. 806-815, Oct. 2014.

[26] T. B. Britton, H. Liang, F. P. E. Dunne, and A. J. Wilkinson, "The effect of crystal orientation on the indentation response of commercially pure titanium: experiments and simulations," Proc. R. Soc. Lond. Math. Phys. Eng. Sci., vol. 466, no. 2115, pp. 695-719, Mar. 2010.

[27] F. K. Mante, G. R. Baran, and B. Lucas, "Nanoindentation studies of titanium single crystals," Biomaterials, vol. 20, no. 11, pp. 1051-1055, Jun. 1999.

[28] B. X. Liu, L. J. Huang, B. Wang, and L. Geng, "Effect of pure Ti thickness on the tensile behavior of laminated Ti-TiBw/Ti composites," Mater. Sci. Eng. A, vol. 617, pp. 115-120, Nov. 2014.

[29] T. Saito, T. Furuta, J.H Hwang, S. Kuramoto, K. Nishino, N. Suzuki, R.Chen, A. Yamada, K. Ito, Y. Seno, T. Nonaka, H. Ikehata, N. Nagasako, C. Iwamoto, Y. Ikuhara, T. Sakuma, "Multifunctional Alloys Obtained via a Dislocation-Free Plastic Deformation Mechanism," Science, vol. 300, no. 5618, pp. 464-467, Apr. 2003.

[30] Y. T. Lee and G. Welsch, "Young's modulus and damping of Ti6Al4V alloy as a function of heat treatment and oxygen concentration," Mater. Sci. Eng. A, vol. 128, no. 1, pp. 77-89, Aug. 1990. 